\title{
NITROGÊNIO E POTÁSSIO NA PRODUTIVIDADE E QUALIDADE DA BANANEIRA CULTIVAR THAP MAEO $\left({ }^{1}\right)$
}

\author{
ADÔNIS MOREIRA $\left({ }^{2 *}\right)$; JOSÉ CLÉRIO REZENDE PEREIRA $\left({ }^{3}\right)$; \\ ALFREDO RIBEIRO DE FREITAS $\left({ }^{2}\right)$
}

\begin{abstract}
RESUMO
O experimento foi realizado em Latossolo Amarelo distrófico da Amazônia Central e teve por objetivo verificar o efeito de doses nitrogênio e de potássio sobre a produtividade e a qualidade dos frutos da bananeira cultivar Thap Maeo (triplóide - AAB). O delineamento experimental utilizado foi o de blocos casualizados em esquema fatorial $3 \times 4$, com os seguintes tratamentos: três doses de $\mathrm{N}(0,267$ e $534 \mathrm{~kg} \mathrm{ha}^{-1}$ ciclo - fonte: uréia) e quatro doses de $\mathrm{K}_{2} \mathrm{O}\left(200,800,1600\right.$ e $2400 \mathrm{~kg}^{-1}$ ciclo - fonte: cloreto de potássio), com três repetições e dois ciclos de colheita. Pelos resultados, constatou-se que o diâmetro do fruto, pH e sólidos solúveis totais não foram influenciados pelas doses de $\mathrm{N}$ e $\mathrm{K}_{2} \mathrm{O}$. A partir do segundo ciclo, independentemente da dose de $\mathrm{N}$, a aplicação de altas concentrações de potássio diminuiu a resistência da polpa. O aumento das doses de $\mathrm{N}$ até $534 \mathrm{~kg} \mathrm{ha}^{-1}$ reduziu a produtividade. No segundo ciclo houve interação significativa entre as doses de $\mathrm{N}$ e de $\mathrm{K}_{2} \mathrm{O}$, sendo a maior produção obtida com aplicação de $1600 \mathrm{~kg} \mathrm{ha}^{-1}$ de $\mathrm{K}_{2} \mathrm{O}$.
\end{abstract}

Palavras-chave: Musa spp., uréia, cloreto de potássio, estado nutricional, Amazônia Central.

\section{ABSTRACT \\ NITROGEN AND POTASSIUM ON YIELD AND QUALITY OF BANANA CULTIVAR THAP MAEO}

The experiment was carried out in a Xanthic Ferralsol (dystrophic Yellow Latosol) of Central Amazon with the objective to verify the effect of nitrogen and potassium rates on yield and quality of banana cultivar Thap Maeo (triploid - AAB). The experimental design was factorial randomized blocks (3x4), with the following treatments: three $\mathrm{N}$ rates $(0,267$ and $534 \mathrm{~kg}$ per ha cycle - source: urea) and four $\mathrm{K}_{2} \mathrm{O}$ rates $(200,800,1600$ and $2400 \mathrm{~kg}$ per ha cycle - source: potassium chloride), with three replicates and two cycles of harvest. The results showed that $\mathrm{N}$ and $\mathrm{K}$ rates did not affect the diameter of fruits, acidity and total soluble solids. After the first cycle, regardless of $\mathrm{N}$ rates, the application of $\mathrm{K}_{2} \mathrm{O}$ rates reduced the resistance of pulp. Banana yield reduced with increased $\mathrm{N}$ rates. In the second cycle, $\mathrm{K}_{2} \mathrm{O}$ rates showed significant interaction with $\mathrm{N}$, and the largest yield was obtained with application of 1600 $\mathrm{kg} \mathrm{ha}^{-1}$ of $\mathrm{K}_{2} \mathrm{O}$.

Key words: Musa spp., urea, potassium chloride, mineral nutrition, Central Amazon.

( $\left.{ }^{1}\right)$ Recebido para publicação em 15 de junho de 2007 e aceito em 6 de fevereiro de 2009

$\left({ }^{2}\right)$ Embrapa Pecuária Sudeste, Caixa Postal 339, 13560-970 São Carlos (SP). E-mail: adonis@cppse.embrapa.br $\left({ }^{*}\right)$ Autor correspondente; ribeiro@cppse.embrapa.br. Bolsistas do CNPq.

(3) Embrapa Amazônia Ocidental, Caixa Postal 319, 69011-970 Manaus (AM). E-mail: Jose.clerio@cpaa.embrapa.br 


\section{INTRODUÇÃO}

A bananeira é uma planta bastante exigente em fertilizantes, uma vez que, além da grande massa vegetativa, os frutos exportam grandes quantidades de nutrientes (Borges e Silva, 1995). No Brasil, com área estimada de 511 mil hectares, a produção atual é de, aproximadamente, sete milhões de toneladas por ano, o que torna a banana a segunda fruta mais produzida, com consumo per capita ano girando em torno de 37,8 quilos (IвGE, 2007).

Semelhantes às outras regiões tropicais onde predominam populações sócio-economicamente carentes, na Amazônia, a banana deixa de exercer o papel de fruta para constituir-se em alimento básico. Apesar dessa vital importância, quase a totalidade dos bananais instalados não recebem adubação, não são feitos os desperfilhamentos e nem a desfolha, entre outras práticas, acarretando em produtividades baixas, em torno de $9 \mathrm{t} \mathrm{ha}^{-1} \mathrm{ano}^{-1}$ (Pereira et al., 2000).

Mesmo com essa importância regional, em Manaus, $50 \%$ da demanda é atendida com a importação de outros Estados, os demais $50 \%$ são provenientes de pequenos produtores oriundos de municípios próximos a Manaus e de outros que distam cerca de $1000 \mathrm{~km}$ (Pereira et al., 2002). Como o meio predominante de transporte na região é o fluvial, a produção dessas localidades demora pelo menos cinco dias para atingir o mercado consumidor, o que reduz a qualidade das frutas, devido, principalmente, ao acondicionamento dos cachos em altas temperaturas nos porões das embarcações.

No caso do estado nutricional, emlevantamento realizado em bananais de seis municípios amazonenses produtores, verificou-se que, independentemente da cultivar, existe carência generalizada de $\mathrm{N}$ e $\mathrm{K}$ e outros nutrientes (MOREIRA et al., 2004). Sabe-se que o nitrogênio (N) juntamente com o potássio $(\mathrm{K})$ são os macronutrientes mais exigidos pela bananeira (SILva et al., 1999) e segundo LAHAV e TURNER (1983), em ordem decrescente, absorve os seguintes macronutrientes: $\mathrm{K}>\mathrm{N}>\mathrm{Ca}>\mathrm{Mg}>\mathrm{S}>\mathrm{P}$ e micronutrientes: $\mathrm{Cl}>\mathrm{Mn}>\mathrm{Fe}>\mathrm{Zn}>\mathrm{B}>\mathrm{Cu}$. Em vários trabalhos têm se observado o efeito da adubação com $\mathrm{N}$ e $\mathrm{K}$ sobre a produtividade, dentre os quais ressaltam-se os realizados por SiLva et al. (1999), Belalcázar e Espinosa (2000) e Silva et al. (2003).

Nas regiões produtoras, as doses de $\mathrm{N}$ recomendadas para bananeira variam de 100 a 600 $\mathrm{kg}^{-1} \mathrm{ha}^{-1}$ ano $^{-1}$ de $\mathrm{N}$, dependendo das condições edafoclimáticas (LÓPEZ e EsPINOSA, 1995). Com relação ao K, Silva et al. (2003) obtiveram respostas significativas, com produção máxima obtida no $4 .^{\circ}$ ciclo com aplicação de $962,5 \mathrm{~kg}$ de $\mathrm{K}_{2} \mathrm{O}$ ha $^{-1} \mathrm{ano}^{-1}$.
Sendo no Estado do Amazonas a adubação incipiente, a deficiência aguda de $\mathrm{K}$ ou murcha abiótica (PEREIRA et al., 2000) é frequentemente notada em bananais estabelecidos em solos de terra firme (Latossolos e Argissolos) e de várzea (Espodossolos), e muitas vezes confundida com os sintomas externos bastante semelhantes aos do moko ou murcha bacteriana (Pseudomonas solanacearum E.F. Smith, raça 2) e ao do mal-do-panamá (Fusarium oxysporum $\mathrm{f}$. sp cubense, Smith), doenças endêmicas na região.

A importância econômica da cultura está inversamente relacionada com a incidência de deficiência nutricional. O cacho da bananeira nessas condições permanece raquítico, com frutos de qualidade inferior, com maturação desuniforme com aspecto visual ruim, sendo pouco aceitas no mercado consumidor (Pereira et al., 2000). Além disso, o desbalanço do $\mathrm{N}$ e K pode causar problemas de póscolheita, levando à queda prematura dos frutos amadurecidos no cacho e produção de frutos magros (SiLva et al., 1999). O excesso de $\mathrm{N}$ atrasa a emergência do cacho, o que favorece a produção de cachos fracos e pencas separadas (SiLva et al., 2003). SiLva et al. (1999) relatam também, que a relação $\mathrm{N} / \mathrm{K}$ nas folhas de bananeira é de grande importância, sendo a mais favorável no florescimento, em torno de 1,4 a 3,3, dependendo da cultivar.

Devido à carência de informações sobre nutrição e adubação dos bananais para as condições edafoclimáticas do Estado do Amazonas, este trabalho teve por objetivo verificar o efeito de doses nitrogênio e de potássio sobre a produção e a qualidade dos frutos da bananeira cultivar Thap Maeo.

\section{MATERIAL E MÉTODOS}

O trabalho foi realizado no período de 2002 e 2003 em Latossolo Amarelo distrófico, em área de terra firme, na área experimental da Embrapa Amazônia Ocidental, localizado no município de Manaus, nas coordenadas geográficas $3^{\circ} 8^{\prime} \mathrm{S}$ e $59^{\circ} 52^{\prime}$ W, Estado do Amazonas. O clima dominante é o tropical úmido tipo Afi pela classificação de Köppen, com chuvas relativamente abundantes durante todo o ano (2622 mm - média de 1971 a 1993); a quantidade de chuva no mês de menor precipitação pluvial sempre superior a $60 \mathrm{~mm}$. A temperatura média anual da região é de aproximadamente $26^{\circ} \mathrm{C}$ (SCHROTH et al., 1999). A área utilizada no experimento foi de seringal abandonado, sendo destocada com trator de esteira sem a realização de queima do material vegetal.

O delineamento experimental foi em blocos casualizados em esquema fatorial ( $3 \times 4)$, com os seguintes tratamentos: três doses de N (0, 267 e 534 
$\mathrm{kg} \mathrm{ha}^{-1}$ por ciclo) e quatro doses de $\mathrm{K}_{2} \mathrm{O}(200,800$, 1600 e $2400 \mathrm{~kg} \mathrm{ha}^{-1}$ por ciclo), com três repetições. Cada parcela consistiu de sete touceiras, e a parcela útil foi constituída pelas cinco centrais. As fontes de $\mathrm{N}$ e $\mathrm{K}_{2} \mathrm{O}$ foram a uréia $(44 \%$ de $\mathrm{N})$ e o cloreto de potássio (58\% de K). As adubações com os tratamentos foram parceladas em quatro épocas (planta mãe): segundo, quarto, sétimo e décimo meses após o plantio (1/4 de $\mathrm{N} \mathrm{e}^{1 / 4}$ de $\mathrm{K}_{2} \mathrm{O}$ por aplicação).

Trinta dias antes do plantio, foi realizada a amostragem do solo para análise de fertilidade, com as seguintes características: $\mathrm{pH}$ (água) $=4,3$; $\mathrm{N}$ total $1,55 \mathrm{~g} \mathrm{~kg}^{-1} ; \mathrm{P}$ (Mehlich 1) $=2 \mathrm{mg} \mathrm{dm}{ }^{-3} ; \mathrm{K}$ (Mehlich 1) $=47 \mathrm{mg} \mathrm{dm}^{-3} ; \mathrm{Na}($ Mehlich 1$)=7 \mathrm{mg} \mathrm{dm}^{-3} ; \mathrm{Ca}(\mathrm{KCl}$ $\left.1,0 \mathrm{~mol} \mathrm{~L}^{-1}\right)=2,4 \mathrm{mmol}_{\mathrm{c}} \mathrm{dm}^{-3} ; \mathrm{Mg}\left(\mathrm{KCl} \mathrm{1,0} \mathrm{mol} \mathrm{L}^{-1}\right)=$

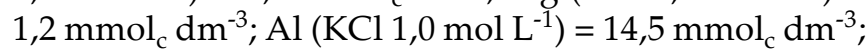
$\mathrm{H}+\mathrm{Al}=80,4 \mathrm{mmol}_{\mathrm{c}} \mathrm{dm}^{-3} ; \mathrm{MO}$ (matéria orgânica) $=$ $46,89 \mathrm{~g} \mathrm{~kg}^{-1}$; $\mathrm{Cu}$ (Mehlich 1) $=0,25 \mathrm{mg} \mathrm{dm}^{-3} ; \mathrm{Fe}$ $\left(\right.$ Mehlich 1) $=333 \mathrm{mg} \mathrm{dm}^{-3} ; \mathrm{Mn}($ Mehlich 1) $=5,15 \mathrm{mg}$ $\mathrm{dm}^{-3}$ e Zn (Mehlich 1) =0,68 mg dm ${ }^{-3}, \mathrm{SB}=5,1 \mathrm{mmol}_{\mathrm{c}}$ $\mathrm{dm}^{-3} ; \mathrm{CTC}=85,5 \mathrm{mmol}_{\mathrm{c}} \mathrm{dm}^{-3} ; \mathrm{V} \%=6,29$ (EMBRAPA, 1997).

Nos experimentos foram feitas as covas com $0,170 \mathrm{~m}^{3}$, onde foram aplicados cinco litros de esterco de galinha e $590 \mathrm{~g}$ de calcário dolomítico $(26,37 \%$ de $\mathrm{CaO}, 12,42 \%$ de $\mathrm{MgO}$ e $\mathrm{PRNT}=77,99)$, o que corresponde a $100 \mathrm{~g}$ para cada tonelada por hectare recomendada pela análise de solo $(\mathrm{V} \%=60)$, não havendo correção do solo em área total. Após 45 dias da aplicação do calcário, foram adicionados juntamente com as mudas da cultivar Thap Maeo [Musa spp. AAB (Silva et al., 1999) - proveniente de cultura de tecidos], 60 gramas de $\mathrm{P}_{2} \mathrm{O}_{5}$ (superfosfato simples) e 50 gramas de FTE bananaâ (fritas com 1,0\% de $\mathrm{B}, 1,0 \%$ de $\mathrm{Cu}, 1,0 \%$ de $\mathrm{Mn}, 0,09 \%$ de $\mathrm{Mo}$ e $18,0 \%$ de $\mathrm{Zn})$.

O espaçamento utilizado foi o de $3 \mathrm{~m}$ entre linhas e $2 \mathrm{~m}$ entre plantas, perfazendo 1667 plantas ha $^{-1}$. Foram realizadas duas adubações de cobertura com 100 gramas de sulfato de magnésio no $4 .^{\circ}$ e $13 .^{\circ}$ mês após o plantio ( $1 .^{\circ}$ e $2 .^{\circ}$ ciclo), e duas com 20 gramas de sulfato de cobre, 20 gramas de sulfato de ferro, 10 gramas de sulfato de manganês; 50 gramas de ácido bórico e 20 gramas de sulfato de zinco no $7 .^{\circ}$ e $15 .^{\circ}$ mês após o plantio, respectivamente. No $1 .^{\circ}$ ciclo, os três primeiros parcelamentos dos tratamentos foram aplicados ao redor da planta; os demais, incluindo os do $2 .^{\circ}$ ciclo, foram realizados em semicírculo ao lado dos perfilhos.

A partir do quinto mês, as plantas foram desperfilhadas, deixando somente uma família (mãe, filha e neta) por touceira. No início do florescimento foi coletada a 'folha 3' (Malavolta, 1992) de cada planta por tratamento e usada para diagnóstico foliar.
No tecido vegetal do $1 .^{\circ}$ e $2 .^{\circ}$ ciclos foram determinados os teores totais de $\mathrm{N}$ e de $\mathrm{K}$ (Malavolta et al., 1997) e no final destes, os teores dos mesmos nutrientes no fruto central da $2 .^{\text {a }}$ penca. O intervalo de colheita do primeiro para o $2 .^{\circ}$ ciclo foi em média, de seis meses.

Após a coleta dos cachos, os frutos foram analisados quanto à produtividade $\left(\mathrm{kg} \mathrm{ha}^{-1}\right)$, diâmetro do fruto central da $2 .^{\text {a }}$ penca $(\mathrm{mm})$, relação polpa/ casca, número de frutos na penca dois a contar da base, número de pencas por cacho, tamanho do cacho (cm), resistência da polpa (Newton), sólidos solúveis (grau brix) e pH - acidez (SANtos e ChitARRA, 1998; INSTITUTO AdOLFo LutZ, 1985).

Para estimativa da quantidade de $\mathrm{N}$ e $\mathrm{K}$ exportado pelo fruto foi proposta a equação: $\mathrm{Co}_{\mathrm{N}, \mathrm{K}}$ $=$ teor de $\mathrm{N}$ e $\mathrm{K}$ no fruto central da $2 .^{\mathrm{a}}$ penca $\mathrm{x}$ produção de cacho, sendo o resultados expressos em $\mathrm{g} \mathrm{planta}^{-1}$. Na conversão para exportação por hectare (Eh), utilizou-se a fórmula: $\mathrm{Eh}=\left[\left(\mathrm{Co}_{\mathrm{N}, \mathrm{K}} \times 1667\right) /\right.$ 1000], sendo 1667 o número de plantas por hectare, 1000 o fator utilizado para obtenção dos resultados em $k g \mathrm{ha}^{-1}$.

Os resultados das análises dos dados fitotécnicos, $\mathrm{N}$ total e K disponível no solo e do tecido vegetal e dos frutos foram submetidos à análise de variância (ANOVA), teste $\mathrm{F}$, regressão e correlação a $5 \%$ de significância, de acordo com métodos descritos por Pimentel-Gomes e Garcia (2002).

\section{RESULTADOS E DISCUSSÃO}

Observando os resultados da análise de variância dos dados fitotécnicos, notam-se efeito significativo da aplicação de $\mathrm{N}$ sobre o tamanho do cacho no primeiro ciclo e na produtividade, no número de pencas, na relação polpa/casca e resistência da polpa no segundo ciclo. Nos dois ciclos, o diâmetro do fruto, o pH e os sólidos solúveis não foram influenciados pelas doses de $\mathrm{N}$ (Tabela 1). A nãosignificância na produtividade no primeiro ciclo pode ser devido á presença de $1,55 \mathrm{~g} \mathrm{~kg}^{-1}$ de $\mathrm{N}$ na camada de $0-20 \mathrm{~cm}$, o que corresponde a $3,1 \mathrm{t} \mathrm{ha}^{-1}$, ao alto teor de matéria orgânica $\left(46,89 \mathrm{~g} \mathrm{~kg}^{-1}\right)$ e de bactérias de vida livre fixadoras de $\mathrm{N}$ que podem ter suprido as exigências nutricionais iniciais nessa fase de desenvolvimento da bananeira (Borges et al., 1997; BORGES et al., 2002). No segundo ciclo, a produtividade diminuiu com o aumento das doses de N. Resultados similares foram obtidos por Borges et al. (1997) e SILVA et al. (2003), que trabalhando com a cultivar PrataAnã, observaram que altas concentrações de $\mathrm{N}$ favorece o desenvolvimento vegetativo da bananeira em detrimento da produtividade. 
$$
\text { Z }
$$

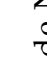

$\frac{1}{0}$

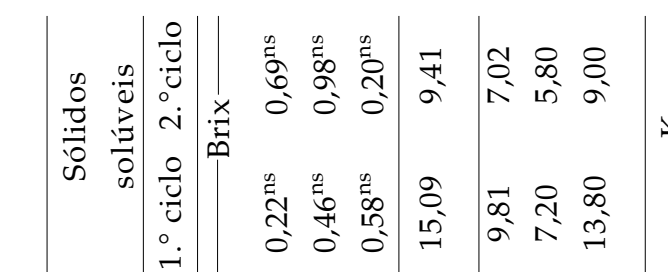

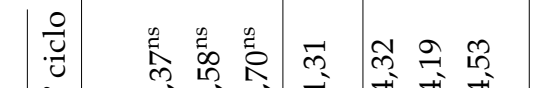
空

$\frac{0}{8}$

总

苞

章

胥

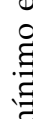

光

:

घิ

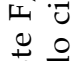

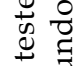

○

s

苛

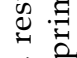

i⿱

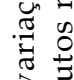

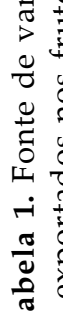

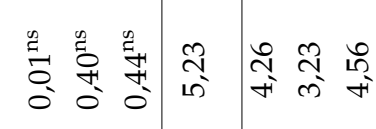

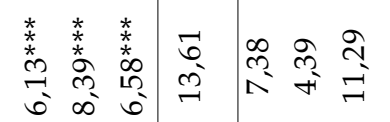

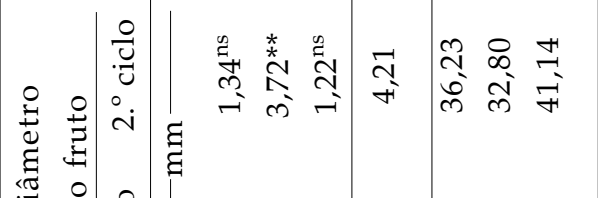

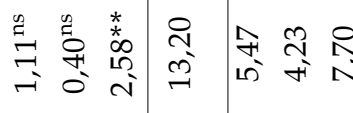

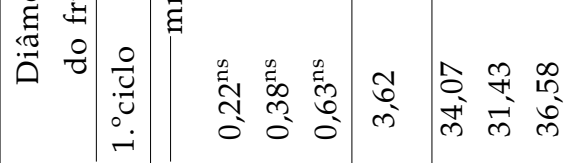

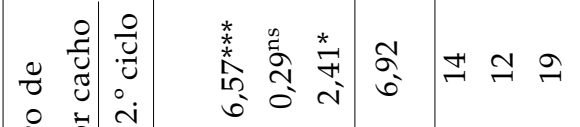
임

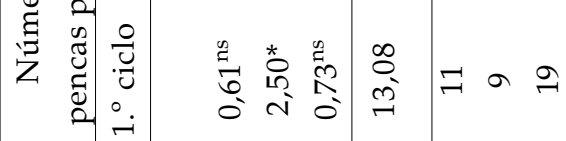

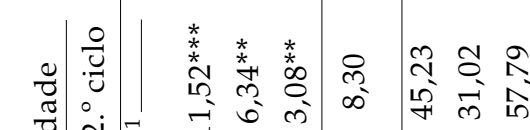
:

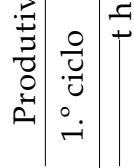

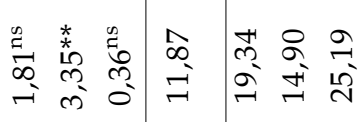

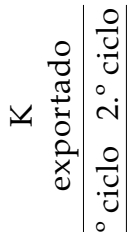

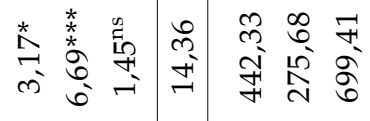

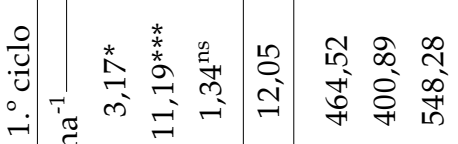

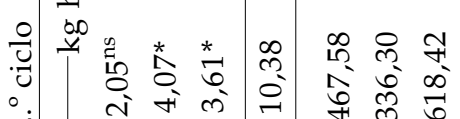
$z$ :

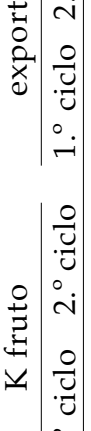

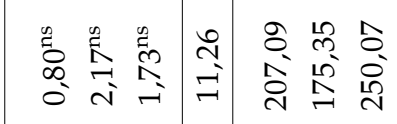

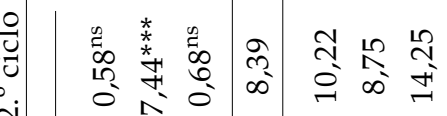

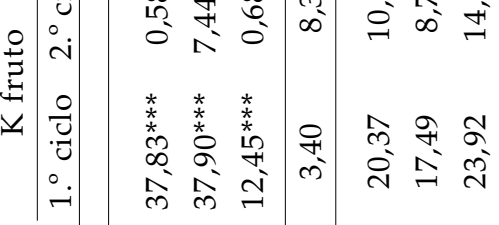

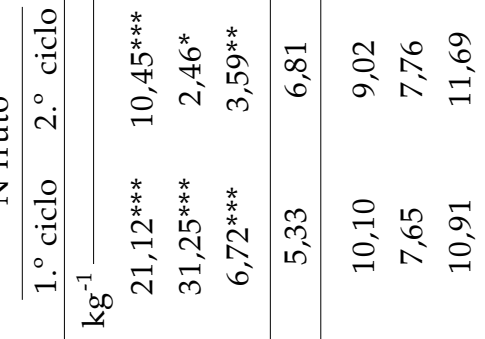

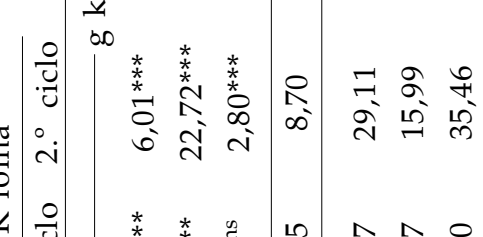
苟 - तु 苞

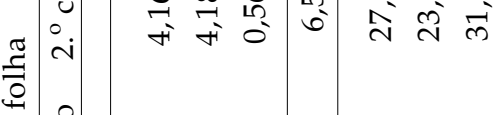

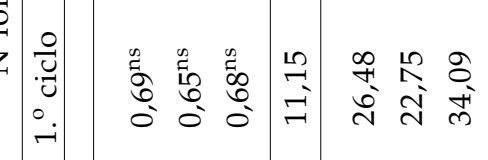

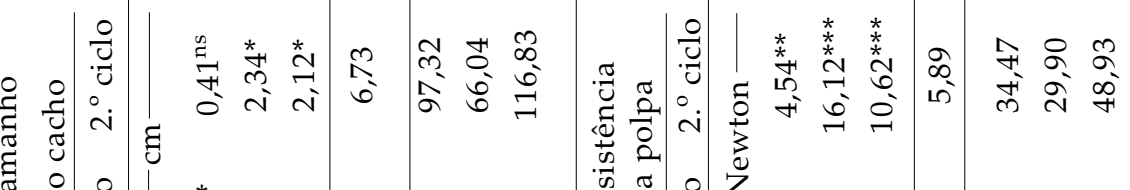

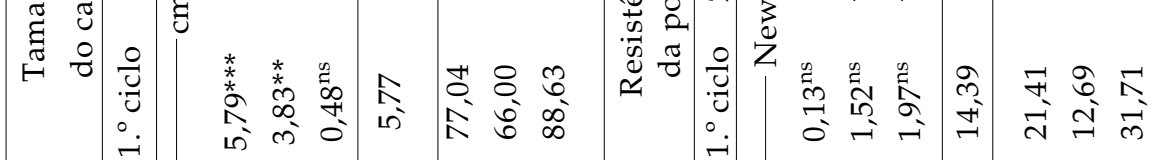




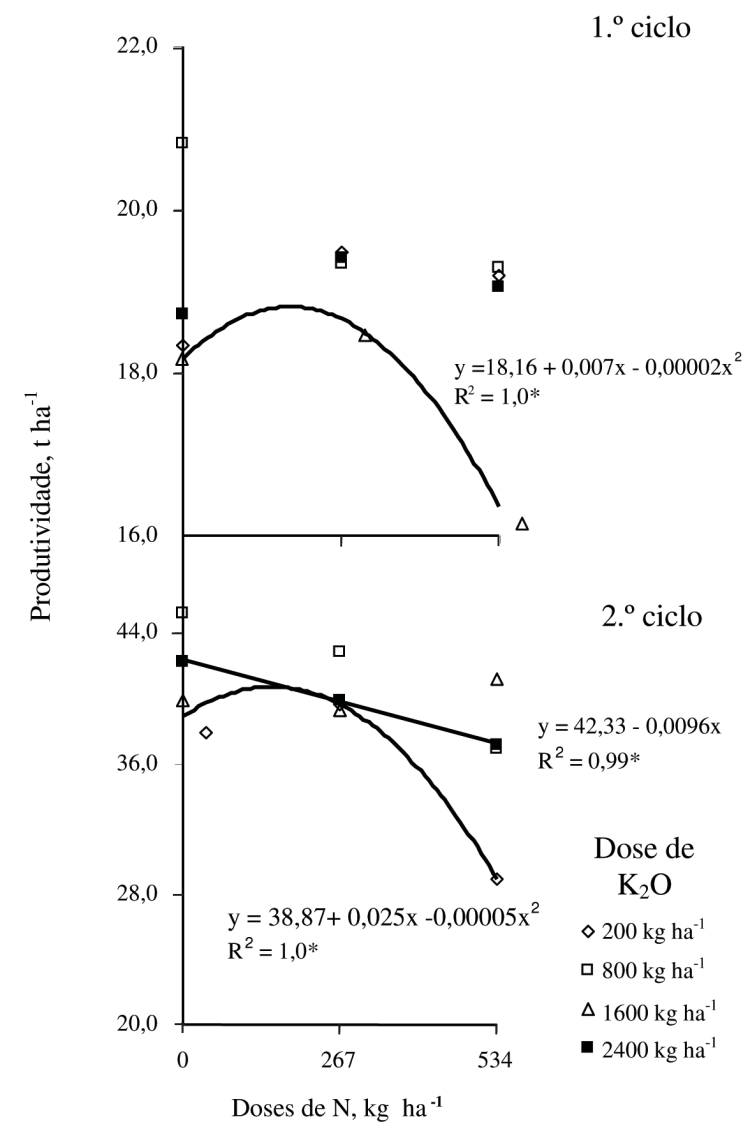

Figura 1. Efeito das doses de $\mathrm{N}$ dentro das doses de $\mathrm{K}$ sobre a produção da bananeira cultivar Thap Maeo. *significativo a $5 \%$ pelo teste $\mathrm{F}$.

Com o aumento das doses $\mathrm{N}$, exceto a dose 800 e $1600 \mathrm{~kg} \mathrm{ha}^{-1}$ de $\mathrm{K}_{2} \mathrm{O}$, cuja resposta não foi significativa (Figura 1), houve no segundo ciclo diminuição na produtividade (Figura 1). Resultados inversos foram obtidos por HedGe e SRINIVAS (1991), em bananal irrigado, no qual verificaram incremento no número de frutos por penca e do número de pencas por cacho. BRAsIL et al. (2000), em cultivo realizado no Estado do Pará, também verificaram no segundo ciclo, efeito significativo da adubação nitrogenada sobre o aumento no peso e número de pencas por cacho.

Os mesmos autores, também observaram que na média dos tratamentos, houve aumento de $134 \%$ na produtividade do primeiro para o segundo ciclo, passando de $19,34 \mathrm{~kg}$ para 45,23 kg (Tabela 1). Havendo também, interação significativa entre $\mathrm{N}$ e $\mathrm{K}$ no segundo ciclo sobre o tamanho do cacho, número de pencas por cacho e produtividade do bananal.

No segundo ciclo (Figura 2), o aumento da produtividade em função dos níveis de $\mathrm{K}_{2} \mathrm{O}$ foi significativa somente dentro da dose $534 \mathrm{~kg} \mathrm{ha}^{-1}$ de N. Para a equação de segundo grau nessa dose, a maior produção foi obtida com aplicação de $1600 \mathrm{~kg}$ $\mathrm{ha}^{-1}$ de $\mathrm{K}_{2} \mathrm{O}$. A não-significância nas outras doses, possivelmente, pode ser devido ao teor de $\mathrm{K}$ disponível no solo após aplicação dos tratamentos, que independentemente da dose usada, estava acima de $196 \mathrm{mg} \mathrm{kg}^{-1}$, valor considerado adequado por MoREIRA et al. (2005) para bananais cultivados nas condições edafoclimáticas do Estado do Amazonas. BRAsIL et al. (2000) também obtiveram resultados positivos na produtividade, com incremento das doses de $\mathrm{K}_{2} \mathrm{O}$. Os mesmos autores verificaram que com aplicação de 622 $\mathrm{kg} \mathrm{ha}^{-1}$, esse valor ficou na ordem de $73 \%$ acima do tratamento sem $\mathrm{K}$, enquanto neste trabalho, apesar do efeito significativo, houve aumento estimado de apenas $8,8 \%$ na produção, obtido na dose $1600 \mathrm{~kg} \mathrm{ha}^{-1}$ quando comparada com a menor dose de $\mathrm{K}_{2} \mathrm{O}$ aplicada (200 kg ha-1) (Figura 2).

A análise de variância dos dados no segundo ciclo indica relação inversa entre a resistência da polpa com as doses de $\mathrm{K}_{2} \mathrm{O}-\mathrm{y}=39,953-0,002 \mathrm{x}, \mathrm{r}=$ $0,48^{*}$ (Tabela 1). Dentro das doses de N, esse resultado é mais acentuado com redução de 38,51 Newton para 32,77 Newton com $0 \mathrm{~kg} \mathrm{ha}^{-1}$ de $\mathrm{N}$, de 48,93 Newton para 36,43 Newton com $267 \mathrm{~kg} \mathrm{ha}^{-1}$ de $\mathrm{N}$ e de 36,24 Newton para 35,76 Newton, com $564 \mathrm{~kg} \mathrm{ha}^{-1}$ de $\mathrm{N}$ respectivamente.

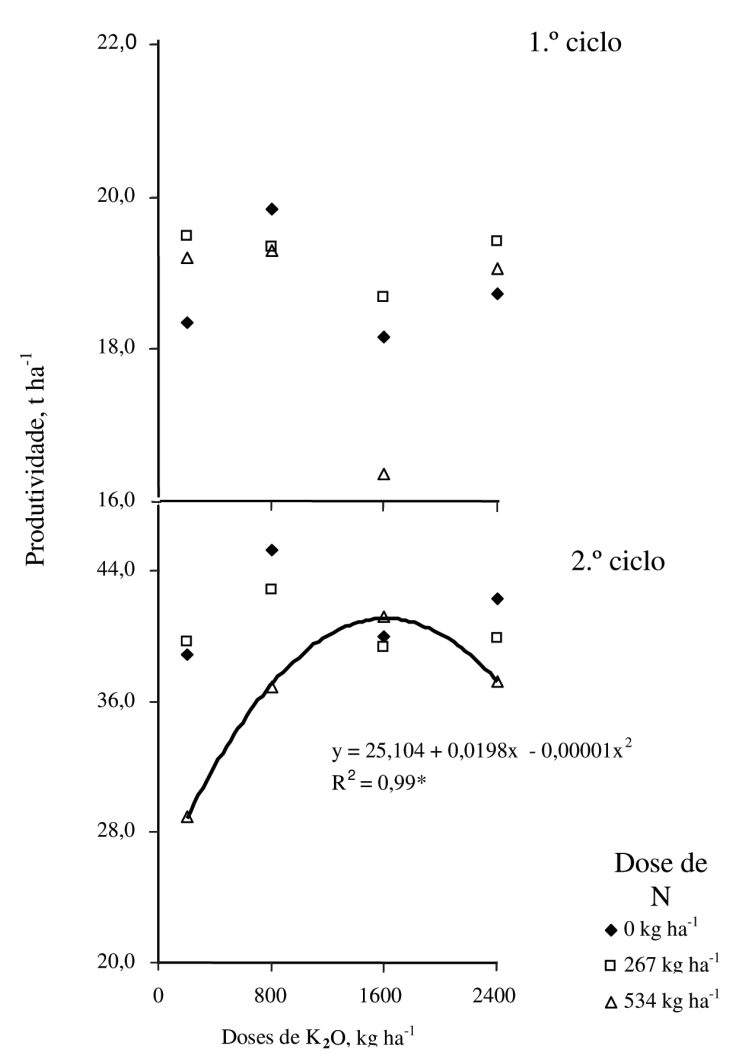

Figura 2. Efeito das doses de $\mathrm{K}_{2} \mathrm{O}$ dentro das doses de $\mathrm{N}$ sobre a produção da bananeira cultivar Thap Maeo. *significativo a $5 \%$ pelo teste $\mathrm{F}$. 
O K desempenha papel importante no processo de regulação osmótica da planta (MARSCHNER, 1995), visto que com o acúmulo do nutriente no vacúolo da célula ocorre um aumento do potencial osmótico, provocando a entrada de água e maior flacidez no tecido, o que, possivelmente, deve ter interferido na resistência da polpa.

Pelos resultados inseridos na tabela 1 , observase efeito significativo da interação $\mathrm{N}$ e K sobre a relação polpa/casca. Nas doses de $800 \mathrm{~kg} \mathrm{ha}^{-1}$ de $\mathrm{K}_{2} \mathrm{O}$ no primeiro ciclo e as doses de 200, 1600 e $2400 \mathrm{~kg} \mathrm{ha}^{-1} \mathrm{de}$ $\mathrm{K}_{2} \mathrm{O}$ no segundo ciclo, a aplicação de $\mathrm{N}$ diminuiu essa relação, enquanto nos demais tratamentos não houve efeito significativo. Com relação ao K, o incremento das doses diminuiu a relação polpa/casca, independentemente das doses de $\mathrm{N}$ e do ciclo de colheita.
No primeiro ciclo, o teste $\mathrm{F}$ indicou ausência de efeito da aplicação de $\mathrm{N}$ dentro das doses 200 e $2400 \mathrm{~kg} \mathrm{ha}^{-1}$ de $\mathrm{K}_{2} \mathrm{O}$ sobre o teor foliar e dentro das doses 200 e $800 \mathrm{~kg} \mathrm{ha}^{-1}$ de $\mathrm{K}_{2} \mathrm{O}$ no teor de $\mathrm{N}$ nos frutos, enquanto no segundo ciclo, as doses de $\mathrm{N}$ afetaram o teor foliar somente na dose $200 \mathrm{~kg} \mathrm{ha}^{-1}$ de $\mathrm{K}_{2} \mathrm{O}$, o inverso ocorreu com o teor $\mathrm{N}$ nos frutos (Figura 3). Silva et al. (2003) não observaram interação $\mathrm{N} x \mathrm{~K}$ sobre o teor foliar de $\mathrm{N}$, havendo efeito isolado somente das doses de $\mathrm{N}$ no segundo ciclo. Com relação ao $\mathrm{N}$ nos frutos, verificou-se que os teores constatados no primeiro e no segundo ciclos foram maiores que os $7,5 \mathrm{~g} \mathrm{~kg}^{-1}$ de $\mathrm{N}$ obtidos por ChACín et al. (1999), com a 'Grande Naine' Musa AAA (Tabela 1).
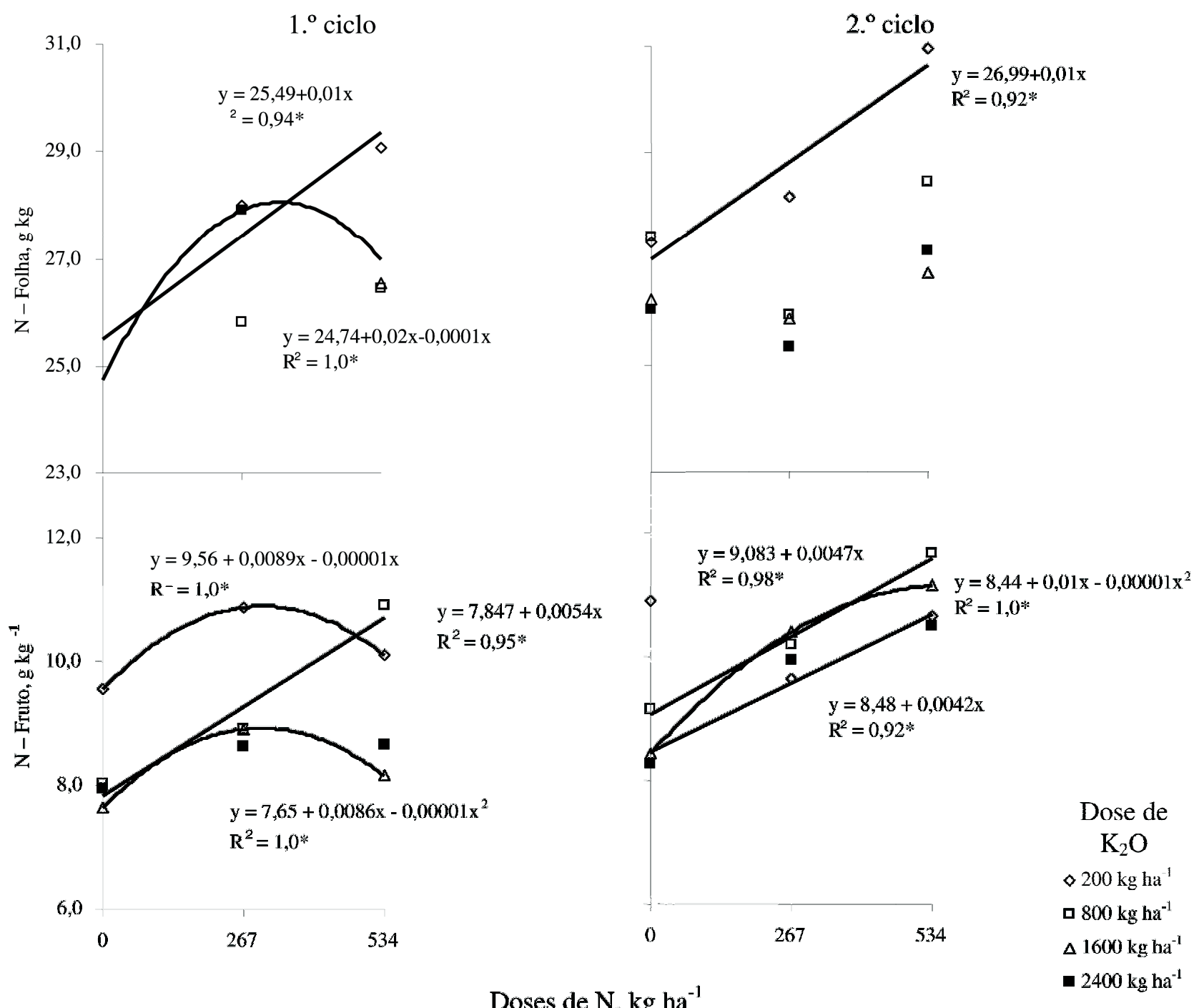

Figura 3. Efeito das doses de $\mathrm{N}$ dentro das doses de $\mathrm{K}_{2} \mathrm{O}$ sobre o teor de $\mathrm{N}$ nas folhas diagnóstico e nos frutos nos dois ciclos de cultivo. *significativo a $5 \%$ pelo teste F. 
No primeiro ciclo, a aplicação de K aumentou de forma quadrática e significativa o teor foliar dentro da dose $534 \mathrm{~kg} \mathrm{ha}^{-1}$ de $\mathrm{N}$, enquanto nas doses 0 e 267 $\mathrm{kg} \mathrm{ha}^{-1}$ de $\mathrm{N}$, não houve significância. No segundo ciclo, independentemente da quantidade de $\mathrm{N}, \mathrm{o}$ incremento nas doses de $\mathrm{K}_{2} \mathrm{O}$ afetou significativamente o teor foliar, sendo linear nas doses 0 e $267 \mathrm{~kg} \mathrm{ha}^{-1} \mathrm{de}$ $\mathrm{N}$ e quadrática com $534 \mathrm{~kg} \mathrm{ha}^{-1}$ de $\mathrm{N}$ (Figura 4). Os teores foliares de $\mathrm{K}$ variaram de $15,77 \mathrm{~g} \mathrm{~kg}^{-1}$ a $46,40 \mathrm{~g}$ $\mathrm{kg}^{-1}$ e de $15,99 \mathrm{~g} \mathrm{~kg}^{-1}$ a $35,46 \mathrm{~g} \mathrm{~kg}^{-1}$, respectivamente, no primeiro e segundo ciclos estando na média com 22,97 $\mathrm{g} \mathrm{kg}^{-1}$ e 29,11 $\mathrm{g} \mathrm{kg}^{-1}$, valores abaixo de $35 \mathrm{~g} \mathrm{~kg}^{-1}$ a $54 \mathrm{~g} \mathrm{~kg}^{-1}$, considerados adequados por MALAVOLTA et al. (1997). O K é de grande mobilidade no solo, e com regime de chuva média anual da região acima de 2.000 mm (Sснготн et al., 1999), ele pode ter sido lixiviado, e grande parte desse fertilizante aplicado ficar indisponível para as plantas.

Semelhante ao teor de $\mathrm{N}$ nos frutos, houve efeito significativo na interação $\mathrm{N}$ e $\mathrm{K}$ no primeiro ciclo, havendo efeito somente do $\mathrm{K}$ no segundo (Tabela 1 ). Nos dois ciclos, exceto a dose $534 \mathrm{~kg} \mathrm{ha}^{-1}$ de $\mathrm{N}$, o modelo com melhor ajuste foi o linear (Figura 4).

Na média, os teores observados no primeiro ciclo corroboram os resultados obtidos por CHACín et al. (1999), enquanto no segundo ciclo foram cerca de $80 \%$ menores que os $18,0 \mathrm{~g} \mathrm{~kg}^{-1}$, constatados pelos mesmos autores, indicando a presença de provável efeito de diluição (Malavolta et al., 1997), haja vista, que a produtividade média foi de $133,9 \%$ maior que a obtida no primeiro ciclo (Tabela 1 ).
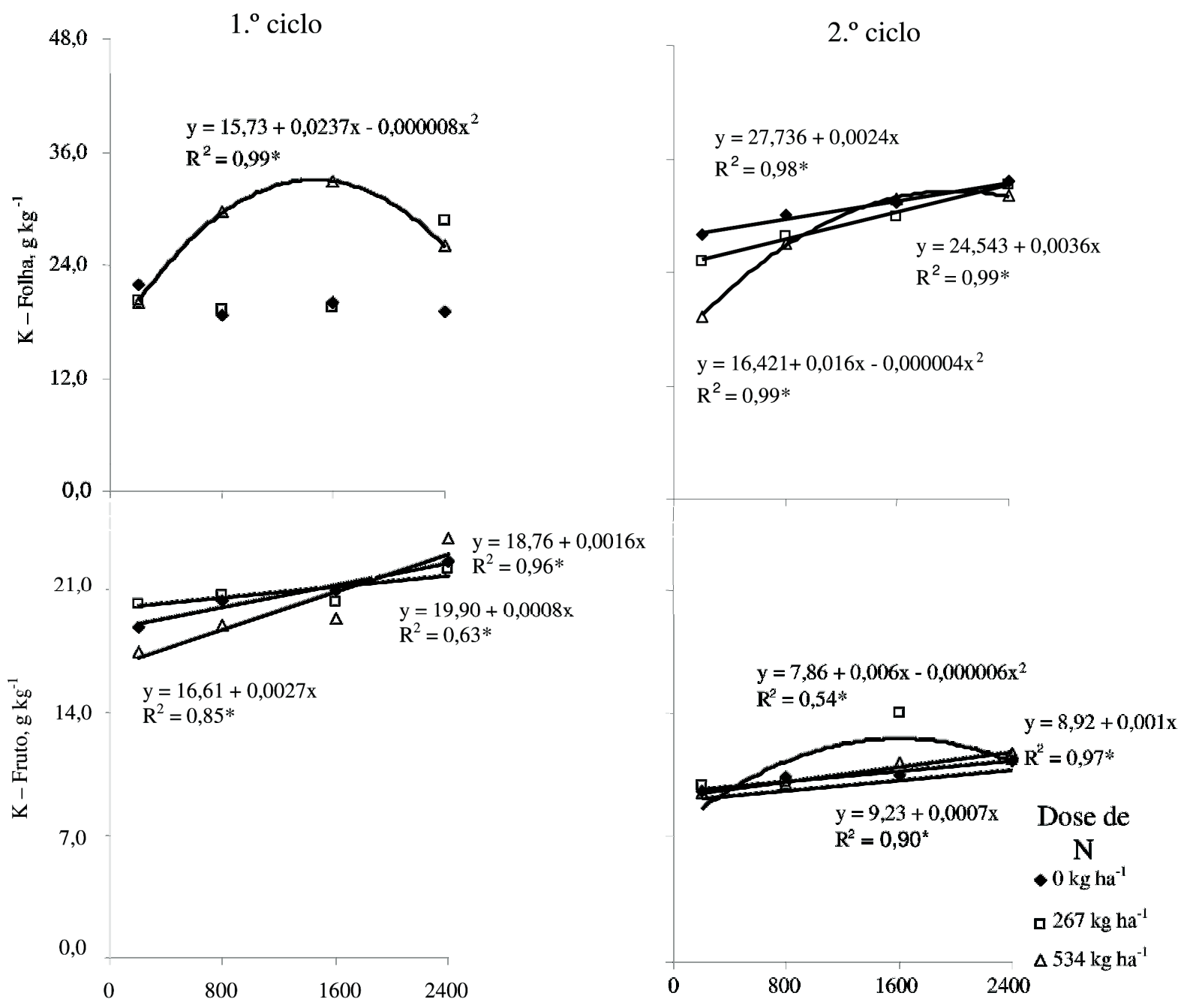

Doses de $\mathrm{K}_{2} \mathrm{O}$, $\mathrm{kg} \mathrm{ha}^{-1}$

Figura 4. Efeito das doses de $\mathrm{K}_{2} \mathrm{O}$ dentro das doses de $\mathrm{N}$ sobre o teor de $\mathrm{K}$ nas folhas diagnóstico e nos frutos nos dois ciclos de cultivo. *significativo a $5 \%$ pelo teste F. 
1. ${ }^{\text {ciclo }}$

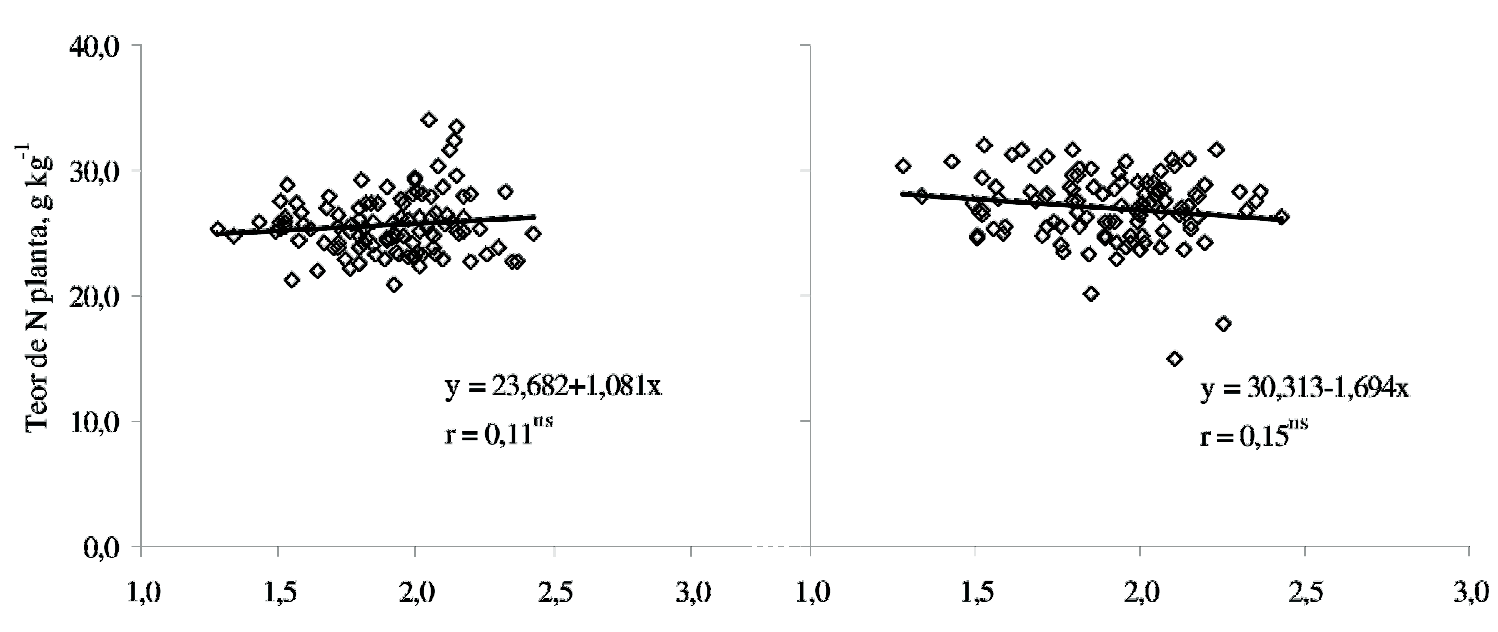

$\mathrm{N}$ total - solo, $\mathrm{g} \mathrm{kg}^{-1}$

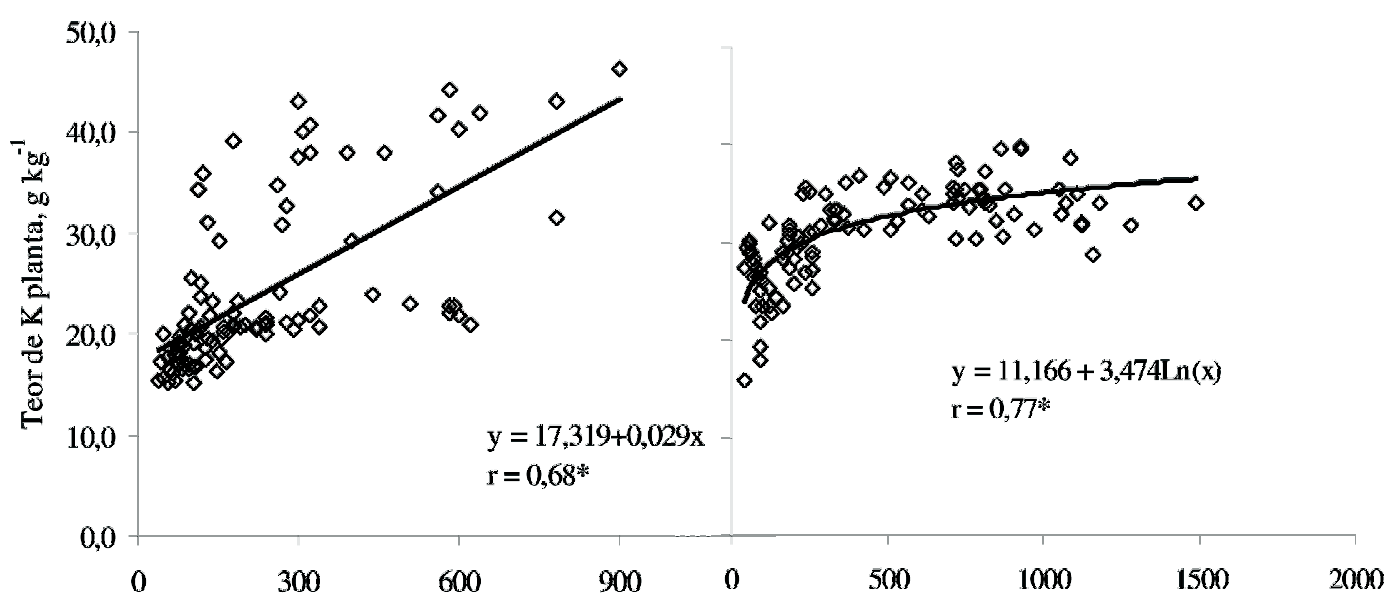

K disponível, $\mathrm{mg} \mathrm{dm}^{-3}$

Figura 5. Correlações entre os teores de $\mathrm{K}$ disponível do solo e teores de $\mathrm{K}$ na folhas diagnóstico e entre o teores de $\mathrm{N}$ total do solo e o teores de $\mathrm{N}$ nas folhas diagnóstico. *significativo a $5 \%$ pelo teste $\mathrm{F}$. ${ }^{\text {ns }}$ não significativo.

Os teores de $\mathrm{N}$ e $\mathrm{K}$ nos frutos foram menores no segundo ciclo, acompanhando inversamente o aumento da produtividade (Tabela 1). Mesmo com menores teores, os frutos no segundo ciclo retiraram do sistema maiores quantidades de $\mathrm{N}$ e $\mathrm{K}$, sendo na média, respectivamente, de $162,4 \%$ e $25,3 \%$ maiores que o exportado no primeiro ciclo. As quantidades de $\mathrm{N}$ e $\mathrm{K}$ extraídas pelos frutos com a cultivar Thap Maeo, na média dos dois ciclos, foram 4,34 e 3,82 vezes superiores às obtidas por BORGES e Silva (1995) nas condições edafoclimáticas do Recôncavo Baiano, com a cultivar Mysore do mesmo grupo genômico (triplóide $\mathrm{AAB}$ ).
Nos teores de K disponíveis obtidos com o extrator Mehlich 1 observou-se correlação significativa na soma dos dois ciclos com o teor de $\mathrm{K}$ na folha diagnóstico, com aumento do $1 .^{\circ}$ para o $2 .^{\circ}$ ciclo do teor de $\mathrm{K}$ no solo e na folha; o mesmo não ocorreu entre o $\mathrm{N}$ total do solo com o $\mathrm{N}$ total na planta (Figura 5). Tal resultado, possivelmente seja decorrente da grande quantidade de adubo potássico aplicado (até $2400 \mathrm{~kg} \mathrm{ha}^{-1} \mathrm{de}_{2} \mathrm{O}$ ) e da necessidade das plantas que, segundo Lanav e TURner (1983), representa cerca de 50\% dos nutrientes absorvidos pela bananeira. 


\section{CONCLUSÕES}

1. Nos dois primeiros ciclos, o aumento das doses de $\mathrm{N}$ até $534 \mathrm{~kg} \mathrm{ha}^{-1}$ reduz a produção da bananeira cultivada em Latossolo Amarelo distrófico com 46,89 $\mathrm{g} \mathrm{kg}^{-1}$ de matéria orgânica nas condições climáticas da Amazônia Central.

2. No $2{ }^{\circ}$ ciclo há interação significativa entre a dose $534 \mathrm{~kg} \mathrm{ha}^{-1}$ de $\mathrm{N}$ com o K, sendo a maior produção obtida com aplicação de $1600 \mathrm{~kg} \mathrm{ha}^{-1}$ de $\mathrm{K}_{2} \mathrm{O}$.

3. O diâmetro do fruto, acidez $(\mathrm{pH})$ e sólidos solúveis não são influenciados pelas doses de $\mathrm{N}$ e K.

\section{AGRADECIMENTOS}

À Embrapa Amazônia Ocidental pelo apoio logístico e ao CNPq - Programa Norte de Pesquisa e PósGraduação (processo 550732/01-2) pelo suporte financeiro.

\section{REFERÊNCIAS}

BELALCÁZAR, S.; ESPINOSA, J. Effect of plant and nutrient management on plantain yield. Better Crops International, Georgia, v.14, p.12-15, 2000.

BORGES, A.L.; SILVA, S.O. Extração de macronutrientes por cultivares de banana. Revista Brasileira de Fruticultura, Cruz das Almas, v.17, p.57-66, 1995.

BORGES, A.L.; SILVA, J.T.A.; OLIVEIRA, S.L. Adubação nitrogenada e potássica para bananeira cv. Prata Anã produção e qualidade dos frutos no primeiro ciclo. Revista Brasileira de Fruticultura, Jaboticabal, v.19, p.179-184, 1997.

BORGES, A.L.; SILVA, T.O.; CALDAS, R.C.; ALMEIDA, I.E. Adubação nitrogenada para bananeira 'Terra' (Musa sp. AAB, subgrupo Terra). Revista Brasileira de Fruticultura, Jaboticabal, v.24, p.189-193, 2002.

BRASIL, E.C.; OEIRAS, A.H.L.; MENEZES, A.J.E.A.; VELOSO, C.A. Desenvolvimento e produção de frutos de bananeira em resposta à adubação nitrogenada e potássica. Pesquisa Agropecuária Brasileira, Brasília, v.35, p.2407-2414, 2000.

CHACÍN, J.; MORENO, M.; FERNÁNDEZ, L.; DELVILLAR, A. Efecto de la fertilización potásica, cálcica y magnésica sobre el contenido de nutrientes del fruto del banano (Musa AAA, subgrupo Cavendish, clon Gran Enano). Revista de la Faculdad del Agronomia, Maracaibo, v.16, p.102-113, 1999.

EMBRAPA. Manual de métodos de análises de solo. Rio de Janeiro: Embrapa-CNPS, 1997.212p.

IBGE. Instituto Brasileiro de Geografia e Estatística, 2007. www.ibge.gov.br. Acesso em 8 de julho de 2008.

INSTITUTO ADOLFO LUTZ. Normas analíticas: métodos químicos e físicos para análise de alimentos. São Paulo: IAL, 1985, v.1, 533p.
LAHAV, E.; TURNER, D. Banana nutrition. In: GOWEN, S. (Ed.). Bananas and plantains. London: Chapman \& Hall, 1983. p.258-316.

HEDGE, D.M.; SRINIVAS, K. Growth, yield, nutrient uptake and water of banana crops under drip and basin irrigation with $\mathrm{N}$ and $\mathrm{K}$ fertilization. Tropical Agriculture, Trinidad, v.68, p.331-334, 1991.

LÓPEZ, A.; ESPINOSA, J. Manual de nutrición y fertilización del banano. Quito: INPOFOS, 1995. $82 \mathrm{p}$.

MALAVOLTA, E. ABC da análise de solos e folhas. São Paulo: Agronômica Ceres, 1992, 124p.

MALAVOLTA, E.; VITTI, G.C.; OLIVEIRA, S.A. Avaliação do estado nutricional de plantas: princípios e aplicações. Piracicaba: Potafós, 1997. 319 p.

MARSCHNER, H. Mineral nutrition of higher plants. London: CRC Press, 1995. 889p.

MOREIRA, A.; PEREIRA, J.C.R.; ARRUDA, M.R. Levantamento exploratório do estado nutricional dos bananais de seis municípios amazonenses. Revista de Ciências Agrárias, Belém, v.41, p.133-138, 2004.

MOREIRA, A.; ARRUDA, M.R.; PEREIRA, J.C.R.; GASPAROTTO, L.; PEREIRA, M.C.N. Recomendação de adubação e calagem para bananeira no Estado do Amazonas (1 ${ }^{\text {a }}$ aproximação). Manaus: Embrapa Amazônia Ocidental, 2005.22p.

PEREIRA, J.C.R.; GASPAROTTO L.; COELHO, A F.S.; VÉRAS, S.M. Doenças da bananeira no Estado do Amazonas. Manaus: Embrapa Amazônia Ocidental, 2000. 27p.

PEREIRA, M.C.N.; GASPAROTTO, L.; PEREIRA, J.C.R.; LOPES, C.M.D. Manejo da cultura da bananeira no Estado do Amazonas. Manaus: Embrapa Amazônia Ocidental, 2002. 14p.

PIMENTEL GOMES, F.; GARCIA, C.H. Estatística aplicada a experimentos agronômicos e florestais. Piracicaba: FEALQ, 2002. 309p.

SANTOS, J.E.S.; CHITARRA, M.I.F. Relação entre idade do cacho de banana "prata" na colheita e na qualidade dos frutos após a colheita. Pesquisa Agropecuária Brasileira, Brasília, v.33, p.1475-1480, 1998.

SCHROTH, G.; SILVA, L.F.; SEIXAS, R.; TEIXEIRA, W.G.; MACÊDO, J.L.V.; ZECH, W. Subsoil accumulation of mineral nitrogen under polyculture and monoculture plantations, fallow and primary Forest in a ferralitic Amazoinan upland soil. Agriculture, Ecosystems and Environment, Shannon, v.75, p.109-120, 1999.

SILVA, J.T.A.; BORGES, A L.; MALBURGO, J.L. Solos, adubação e nutrição da bananeira. Informe Agropecuário, Belo Horizonte, v.20, p.21-36, 1999.

SILVA, J.T.A.; BORGES, A.L.; CARVALHO, J.G.; DAMASCENO, J.E.A. Adubação com potássio e nitrogênio em três ciclos de produção da bananeira cv. Prata-Anã. Revista Brasileira de Fruticultura, Jaboticabal, v.25, p.152-155, 2003. 